Originally published as:

Marcus, U., Schmidt, A.J., Hamouda, O.

HIV serosorting among HIV-positive men who have sex with men is associated with increased self-reported incidence of bacterial sexually transmissible infections

(2011) Sexual Health, 8 (2), pp. 184-193.

DOI: $10.1071 / \mathrm{SH} 10053$

This is an author manuscript. The definitive version is available at: http://www.publish.csiro.au/ 


\title{
HIV serosorting among HIV-positive men who have sex with men is associated with increased self-reported incidence of bacterial sexually transmissible infections
}

\author{
Ulrich Marcus $^{A, B, C}$, Axel J. Schmidt ${ }^{A, B}$ and Osamah Hamouda ${ }^{A}$ \\ ${ }^{A}$ Robert Koch Institute, Post Box 650261, 13302 Berlin, Germany. \\ ${ }^{B}$ These authors contributed equally to this work. \\ ${ }^{\mathrm{C}}$ Corresponding author. Email: marcusu@rki.de
}

Background: We aimed to quantify the frequency of HIV serosorting among men who have sex with men (MSM) in Germany, and evaluate the association of serosorting with other sexual risk management approaches (RMA) and with the frequency of bacterial sexually transmissible infections (STI).

Methods: An anonymous, self-administered questionnaire was distributed through German online sexual networking sites and medical practices in 2006. The analysis was based on 2985 respondents who reported an HIV test result. Based on two questions on RMA, serosorting was classified as tactical (an event-based decision) or strategic (a premeditated search for a seroconcordant partner). The analysis was stratified by HIV serostatus and seroconcordant partnership status.

Results: HIV serosorting patterns were different for HIV-positive and HIV-negative participants. Tactical serosorting ranked second after RMA based on condom use (HIV-positive: 55.1\%, HIVnegative: 45.1\%; $P<0.001$ ). While the overlap of strategic and tactical HIV serosorting among HIVpositive MSM was substantial (58.0\%), HIV-negative strategic and tactical serosorting were more distinct (18.1\% overlap). Among HIV-positive and HIV-negative respondents, tactical serosorting was associated with reduced condom use. Compared with respondents using RMA other than serosorting, HIV-positive men reporting serosorting had a three-fold increased risk for bacterial STI (strategic: odds ratio $(O R)=2.62 ; 95 \%$ confidence interval $(C l): 1.76-3.89 ;$ tactical: OR= 3.19; 95\% Cl: 2.14-4.75; both for respondents without HIV seroconcordant partners).

Conclusions: HIV serosorting has emerged as a common RMA among MSM. For HIV-positive MSM, it may contribute to high rates of bacterial STI that may lead to elevated per-contact risks for HIV transmission.

\section{Background}

In the past decade, surveys of sexual risk behaviour in men who have sex with men (MSM) in Western post-industrialised countries have demonstrated a number of trends.

The frequency of anal intercourse with non-steady partners and the proportion of MSM with high numbers of sexual partners have increased. However, the frequency of HIV testing has increased as well and hence the precondition for communicating a recent HIV test result. Condom use in anal intercourse with partners of perceived concordant HIV serostatus has been declining. ${ }^{1-11}$ Unprotected anal intercourse (UAI) with presumably seroconcordant sexual partners has been labelled serosorting, especially with nonsteady partners, or negotiated safety with steady partners. Serosorting has the potential to reduce the frequency of UAI with serodiscordant partners. ${ }^{12}$ However, fundamental differences between HIV-positive and HIV-negative serosorting need to be considered: while an explicitly communicated positive HIV status is usually highly reliable information, a reported negative HIV status may or may not be true, either because people do not always tell the truth or because they have seroconverted since their last negative HIV test. ${ }^{13,14}$ However, explicit disclosure of a positive HIV status requires barriers posed by stigma and fear to be overcome.15 This means that serosorting of HIV-positive MSM comprises features of stigma management as well as risk management, while serosorting of HIV-negative men is predominantly risk management. Because meaningful disclosure of HIV serostatus requires a certain degree of mutual trust, intended serosorting - particularly if employed in the context of casual, often anonymous, partnerships - in practice may be described as seroguessing ${ }^{16,17}$ and is thus prone to error. 
Serosorting - especially if employed predominantly by MSM with many sexual partners or within larger sexual networks - may enhance epidemics of other sexually transmissible infections (STI) and thus contribute to an increase in the percontact transmission probability of HIV. ${ }^{16-27}$

The estimated number of MSM newly diagnosed with HIV in Germany doubled from 1100 in 2000-01 to 2200 in 2008-09. Confronted with these increasing numbers, we designed and implemented a national survey on knowledge, attitudes and behaviour as to sexually transmitted infections (the KABaSTI study) for MSM. In this report, to explore the potentially unintended consequences of HIV serosorting, we aimed (1) to quantify the proportion of MSM reporting their intentions to serosort when asked about their personal HIV risk (or stigma) management approaches (RMA); (2) to describe the behavioural context, i.e. the association between serosorting and other RMA; and (3) to analyse the inter-relationship between serosorting and recent diagnoses of bacterial STI. In this analysis, we used reported intention to serosort as a surrogate for the practice of HIV serosorting, which is particularly difficult to measure by self-reported behaviour with non-steady partners. Measurement problems can arise from difficulties in capturing explicit and implicit serostatus communication between partners using a limited set of questions in a behavioural survey. Moreover, the validity of an HIVnegative serostatus reported during a sexual encounter is difficult to determine.

Risk management approaches that imply selective condom use have not yet been consensually put into use in behavioural questionnaires. Therefore we contrast two different ways of querying serosorting, with possible consequences for future quantitative research on sexual behaviour among MSM.

\section{Methods}

\section{Participants}

The study used two approaches to recruit participants:

(1) German languageMSMonline sexual networking sites were asked to provide a link to an online questionnaire in June 2006. Seven websites participated. The mode of advertisement ranged from individual messages to website users, to providing a prominent banner on the start page or providing a more hidden banner on a secondary page on health information.

(2) More than 300 doctors in private medical practices $(n=318)$ who had reported syphilis infections among MSM since 2001 within the German infectious disease surveillance

system were asked to participate in the study. Most STIrelated health care in Germany is provided by private practices (for men, mostly general practitioners, dermatologists and urologists, or, in larger cities, in specialised HIV centres). Participating practices ( $n=76 ; 24 \%)$ received print questionnaires for distribution to all identifiable MSM clients from May to August 2006, regardless of the reason for consultation. Participants were asked to complete the questionnaire anonymously and to return it by mail postage prepaid.

Thus, the sample frame was a convenience sample of German-speaking MSM aged 16 years and older. Material or monetary incentives for participation were not provided, neither to the MSM who participated in the study nor to private practices that recruited patients.

The study was approved by the ethics committee of the Charité University Clinics in Berlin.

\section{Questionnaire}

An anonymous self-administered online and print questionnaire consisting of 66 items was used. The questions included sociodemographic data, current steady relationship with a man, sexual behaviour with steady partners and other partners, attitudes and risk management approaches regarding prevention of HIV and STI, history of STI, history of HIV testing, and - if tested for HIV antibodies - the last test result.

\section{Measures}

Serosorting is not an established concept that can easily be measured in behavioural surveys. Studies dealing with serosorting have to be compared with caution, as it is not always clear how it has been queried and put into use. In some studies, serosorting is seen as a more generalised way of seeking sexual contacts exclusively or preferably with partners of the same serostatus; while in other studies, 
serosorting is defined as non-use of condoms in a specific sex act because of assumed seroconcordance. We labelled the generalised approach strategic serosorting and the situational approach tactical serosorting.

Questions analysed and definitions

We included the following three questions on sexual behaviour in the previous 12 months into our analysis:

(1) How many men did you have sex with in the previous 12 months? Response options were: none, 1, 2-5, 6-10, 11-20, 21-50, 51-100 or more than 100.

(2) How many of your sex partners in the previous 12 months were anonymous partners? (Anonymous means the only way to meet this person again would be by chance.) Response options were all of them, most of them, more than half, less than half, some of them or none of them.

(3) Did you have anal intercourse without a condom in the previous 12 months with a sex partner whose HIV test result you did not know? If yes, how often did this happen in the previous 12 months? Response options were once or twice, 3-4 times, 5-10 times, every month, or every week or almost every week. The three following categories of partners for this question were: steady partner, nonsteady but known partner and non-steady previously unknown partner.

Risk management approaches were queried with essentially two questions. In one multiple choice question, respondents were asked: 'What is your response to the risk of infections during sexual contacts?' We offered a choice of 12 responses; multiple responses were allowed. In another multiplechoice question, participants were asked: 'Under which conditions would you decide not to use a condom for anal intercourse?' We offered a choice of eight responses; again multiple responses were allowed.

All RMA included in statistical analyses are described and summarised in Table 1.

Classification as HIV-positive or HIV-negative, or as currently being treated with antiretroviral therapy (ART) was based on self-reported information.

A recent diagnosis of a bacterial STI was defined as self-reported syphilis, chlamydia infection, or selfreported urethral, pharyngeal, or anal gonorrhoea during the previous 12 months.

\section{Stratification}

Both groups, strategic and tactical serosorters, were stratified (1) by HIV serostatus and (2) by the type of sexual partners. The concepts of steady and other partners were self-defined, but clearly separated in the questionnaire as different categories of sex partners. This stratification was deemed necessary because participants with a seroconcordant steady partner may have practiced negotiated safety (serosorting only within a relationship with a high reliability of serostatus information). As the questions on RMA, including serosorting, did not systematically distinguish between sexual contacts with steady and non-steady partners, the four serosorting strata of respondents who reported a seroconcordant steady partner were analysed separately from respondents who reported only nonsteady partners and serodiscordant or 'serostatus unknown' steady partners in the previous 12 months.

Relationship between different dimensions of sexual risk management and HIV serosorting

We grouped variables from the questionnaire into sexual behaviour (number of partners in previous 12 months, proportion of anonymous partners, UAI with partners of unknown HIV serostatus) and risk management approaches with the following different dimensions of risk management: partner restriction (monogamy), partner selection (face check), condom use intentions (safer sex,A partner decision, extended condom use for STI prevention), restriction of active body fluid exchange (withdrawal) and positioning in anal intercourse (strategic positioning). We compared the two groups who reported serosorting intentions, stratified by HIV-serostatus, with their control groups with respect to these 10 variables. 


\section{Analysis}

For this analysis, we included only those respondents who had answered the question on HIV-testing, who reported an HIV test result, and who had answered the questions on RMA and previous STI.

For analysing of the impact of serosorting on the incidence of bacterial STI among the respondents, we calculated the odds ratio (OR) for reporting a bacterial STI within the previous 12 months for the various strata of strategic and tactical serosorters, and the respective control groups of respondents reporting RMA other than serosorting (i.e. this question was analysed in eight different strata of serosorters).

We used multivariate logistic regression (SPSS 16; SPSS Inc., Chicago, IL, USA) for calculating adjusted OR to describe the relationship between sexual behaviour variables, RMA and serosorting (Table 3), and for reporting a recent diagnosis of bacterial STI (Table 4). Adjustments were made for age (stratified as 16-24 years old, 25-34 years, 35-44 years and 45 years or older) and recruitment site (practice, general MSM dating site, bareback site).

\section{Results}

\section{Survey participants}

After exclusion of respondents who did not meet the inclusion criteria, data from 2985 respondents could be analysed. Respondents who were excluded $(n=3665)$ had either not reported previous HIV testing, which basically was due to early dropout before reaching the question $(n=3371)$, or had not reported an HIV test result $(n=67)$ or had not answered the critical questions concerning serosorting approaches $(n=215)$ or diagnosis of STI in the previous 12 months $(n=12)$.

The basic characteristics of the remaining respondents are presented in Table 2. Participants represented a broad spectrum of age (16-76 years) and geographical distribution. Approximately half of the HIV-positive online participants were recruited on a bareback website whose clients had an eight-fold higher HIV prevalence (54\%) than clients of the other websites (7\%).

The behavioural context of HIV serosorting in survey respondents

Sexual behaviour: number and type of sexual partners

More than five male sexual partners within the previous 12 months were reported by $54 \%$ of the respondents, and more than 10 by $38 \%$. The proportion of participants with more than 10 sexual partners was higher among HIV-positive men than among HIV-negative men (see Table 2). Among participants who were older than 24 years, $44 \%$ reported that the majority of their sexual partners were anonymous; in participants younger than 25 years, the proportion reporting a predominance of anonymous partners was only $22 \%$. While there were differences in partner numbers between HIVpositive and HIV-negative participants, the frequencies of sexual intercourse were very similar (data not shown). Partnership status had an impact on frequency of reported sexual intercourse. Men with a steady partner reported more frequent intercourse than men with exclusively non-steady partners. A minimum of one episode of UAI with a partner of unknown HIV serostatus was reported by $30.3 \%$ of HIV-negative and $49.8 \%$ of HIV-positive respondents.

Attitudes towards safer sex, condom use, serostatus communication and partner selection When asked about their response to the risk of HIV and other STI, the majority of survey participants (71.9\%) claimed to generally practice safer sex (no definition of safer sex was provided). The proportions for participants whose last HIV test result was negative and participants who reported being HIV-positive are shown in Table 2.

A positive attitude towards condom use for prevention of STI other than HIV was expressed by the majority of survey participants living with HIV.

Within steady relationships, communication about HIV status seemed to be common. Among HIVpositive survey participants living in a steady relationship, $80.6 \%$ knew about the HIV serostatus of their partners (43.1\% HIV seroconcordant; $37.5 \%$ HIV serodiscordant). Among HIV-negative participants, $75 \%$ were aware of an HIV test result of their partner (65.9\% HIV seroconcordant; $9.1 \%$ HIV serodiscordant). We did not ask directly about HIV serostatus disclosure to non-steady partners. 
Self-reported history of STI

Differences in self-reported history of bacterial STI in the previous 12 months were observed according to HIV serostatus (see Table 2) and ART. Among HIV-positive respondents, $71.2 \%$ were receiving ART. Recent bacterial STI were less frequently reported by respondents who were currently receiving ART than by respondents who did not $(28.7 \%$ v. 43.9\%; $P<0.001)$.

\section{HIV serosorting Frequency of HIV serosorting approaches}

HIV serosorting patterns were different among HIV-positive and HIV-negative participants, as shown in Table 2. Among RMA, tactical serosorting ranked second after RMA based on condom use.

After stratification for seroconcordant relationships, there were $591 \mathrm{HIV}$-positive participants without a seroconcordant steady partner. Of these, 295 (49.9\%) were classified as practicing tactical serosorting and $198(33.5 \%)$ were classified as practicing strategic serosorting. Among these, 181 HIVpositive men were classified as both strategic and tactical serosorters.

Among the 1456 HIV-negative participants without a seroconcordant steady partner, the overlap was smaller: 636 (43.7\%) were classified as practicing tactical serosorting, and 181 (12.4\%) were classified as practicing strategic serosorting. Among these, 125 HIV-negative men were classified as both strategic and tactical serosorters.

Notably, $39 \%$ of HIV-negative participants and $34 \%$ of HIVpositive participants who reported predominantly practicing safer sex and had no seroconcordant steady partner said that they would not use condoms if they perceived their partner as HIV seroconcordant, which meets our definition of tactical serosorting.

Relationship between different dimensions of sexual risk management and HIV serosorting Strategic and tactical HIV serosorting among HIV-positive respondents.

Among HIV-positive respondents, the associations between strategic and tactical serosorting and other aspects of sexual risk management were highly consistent (see Table 3), reflecting the considerable overlap between the two groups. Compared with HIV-positive respondents with other risk management approaches than serosorting, both groups reported less safer sex, reduced condom use during anal intercourse with non-steady partners or for STI prevention, and higher numbers of sex partners; both were more likely to use strategic positioning and both were more willing to practice unprotected sex if their partner did not insist on condom use.

Strategic and tactical HIV serosorting among HIVnegative respondents.

Comparing HIV-negative strategic and tactical serosorting, the association between other forms of sexual risk management and serosorting was mixed (see Table 3). Compared with the control groups, both tactical and strategic serosorting were associated with the intention to restrict sexual activity to steady relationships, both were associated with checking out potential partners for signs of HIV, and both were associated with the belief that strategic positioning and withdrawal before ejaculation might reduce the risk for HIV infection. Differences were found regarding self-reported HIV risk taking: tactical (but not strategic) serosorting was associated with a history of five or more episodes of anal intercourse with non-steady partners of unknown HIV serostatus and was associated with accepting a partner's decision not to use condoms; it was less often associated with the choice of safer sex as an RMA and with agreeing with the statement that condom use was necessary for protection against other STI.

Impact of HIV serosorting on the risk for bacterial STI

Among HIV-positive respondents, tactical and strategic serosorting was associated with a recent history of bacterial STI. This association was independent from the HIV serostatus of the steady partner. High OR were found for men without a seroconcordant steady partner, as well as for men who had been in a relationship with a man who was also HIV-positive. Contrastingly, no increased risk for bacterial STI was found among HIV-negative men who reported any kind of serosorting (see Table 4).

Sensitivity analysis of the impact of recruitment sites

All results reported in Table 2 remain qualitatively unchanged if we exclude men recruited on the bareback website from analysis, or if OR are not adjusted for recruitment site (Tables 3 and 4). 
However, the differences between HIV-negative and HIV-positive respondents (Table 2) and the calculated OR in Table 3 slightly decline, while the OR presented in Table 4 slightly increase (data not shown).

\section{Discussion}

Among German MSM, we found empirical evidence for a widespread use of risk management and risk reduction approaches other than condom use, primarily HIV serosorting. The proportions of serosorters in our sample are higher than reported from Australia, ${ }^{17}$ which may reflect a broader definition of serosorting in our analysis and sampling differences. Overlapping response patterns indicate that HIV serosorting in a context of non-steady partnerships was interpreted as being consistent with safer sex by many MSM. Like safer sex, these strategies focus predominantly on the risk of HIV and - with the exception of strategic serosorting in HIV-negative MSM (who qualified as avoiders of any contact with HIV-positives rather than serosorters) - were implemented as substitutes for consistent condom use. One may argue whether strategic serosorting in HIV-negative MSM as defined and described in our study is serosorting at all, since it does not seem to substitute condom use but appears to be used as an additional layer of safety by men who are very anxious to avoid the risk of HIV.

Respondents appear to prefer establishing steady relationships with HIV seroconcordant partners. Among other reasons for preferring HIV seroconcordance in partnerships, this allows UAI without the risk of HIV transmission in the absence of HIV risk-taking with third parties. However, partnership status had no obvious impact on the rate of reported bacterial STI in the previous 12 months, either in HIV-positive or in HIVnegative MSM (see Table 4). This may be due to underrepresentation of men living in monogamous relationships in our sample, which was mainly recruited on dating websites. But outside of steady relationships, serosorting was employed for HIV risk management and, for HIVpositive men, presumably rather for stigma management. HIV seroconcordance was the most frequently cited reason for the intention of not using condoms during anal intercourse. HIV-negative men, who reported tactical serosorting as a reason for not using condoms with an assumed seroconcordant partner, often had a current steady partner. We were not able to clearly differentiate how much of this serosorting was actually negotiated safety, as we could not determine whether a decision for not using condoms with the steady partner was the result of a process of mutual disclosure of each other's HIV serostatus and explicit negotiation of the rules of conduct with other partners outside of the steady relationship.

While online communication may reduce the threshold for more explicit and implicit serostatus disclosure for HIV-positive men outside of steady relationships, ${ }^{28-31}$ different meanings and interpretations of codes and surrogates used for HIV serostatus determination may occur during online communication, and have been described. ${ }^{16,31}$ Even more difficult and prone to error is the establishment of HIV seroconcordance between presumably HIV-negative men meeting online, and especially with anonymous non-steady partners met offline. ${ }^{17,32}$ The readiness for not using condoms 'if the partner does not insist on condom use', which, in our survey, was notably reported by HIVpositive as well as HIV-negative respondents, indicates a lack of explicit communication of HIV serostatus 16 and a readiness to base condom use decisions on weakly founded assumptions.

Prevention campaigns will have to address this kind of nonnegotiated unsafe behaviour with messages stressing that assumptions about the HIV serostatus of potential sexual partners should not be based on their willingness to insist on condom use.

We could show that HIV serosorting among HIV-positive men, according to both of our definitions, was associated with a significantly increased incidence of STI. The high incidence of STI is mediated by high partner numbers, reduced condom use and the high prevalence of STI within the sexual networks of HIV-positive people who serosort. The high STI incidence among HIV-positive men also supports the assumption that the positive attitudes towards serosorting that we captured by our questions reflect HIV stigma management rather than effective management of sexual risks.

Among HIV-negative men, tactical serosorting with nonsteady partners was associated with reduced condom use and strategic positioning. While we did not find an increased incidence of bacterial STI, this may still confer considerable risks for the acquisition of HIV, particularly in sexual networks and 
situations where explicit HIV status disclosure is unusual (e.g. if people refer to partner decision on condom use).

Due to the large overlap between strategic and tactical serosorting among HIV-positive MSM and the considerable differences between the two concepts among HIV-negative MSM, it may be advisable to focus in future studies on the interrelationship between HIV serosorting and transmission

risks of HIV and STI on the concept of tactical serosorting, which seems to be more problematic in HIV-negative MSM in terms of HIV transmission risk than strategic serosorting.

It should be mentioned that the self-reported rates of bacterial STI in our sample almost certainly reflect a considerable underdiagnosis. ${ }^{33}$ While relying on self-reports of bacterial STI is a limitation of this analysis, we still believe that different selfreported STI rates reflect actual differences of STI incidence, because at least at the time of the survey (2006), screening for asymptomatic anorectal and pharyngeal infections with Neisseria gonorrhoeae and Chlamydia trachomatis was highly unusual in Germany, even for HIV-positive men in regular care at HIV specialists.

There are a few more limitations for our findings. Our survey participants are a convenience (i.e. nonrepresentative) sample of German-speaking MSM: by recruiting participants in medical practices and by including a bareback website, we intentionally oversampled HIV-positive participants (HIV prevalence in our sample was $\sim 2-2.5$-fold the estimated average prevalence in MSM in Germany ${ }^{34, B}$ ), and participants with a higher than average level of sexual risk behaviour and consequently a higher than average incidence of STI. HIV-positive and HIVnegative MSM who restrict their sexual activity to a steady relationship or who are not sexually active at all are certainly under-represented in our sample. Other limitations are biases in the sample, especially in terms of educational and professional status, not so much in geographical and age distribution. Compared with the general male population of Germany, men older than 50 years and MSM with immigrant backgrounds were under-represented. The sample was also affected by a middle-class bias, which is typically seen in convenience samples. It may be that MSM from lower social classes or other subgroups of MSM who are not reached by internet surveys show different patterns of risk management approaches.

We do not believe that oversampling of HIV-positive participants, and participants with a higher level of sexual risk behaviour entails a problem for our analysis. Our aim was the analysis of tactical and strategic serosorting as risk management approaches among MSM, the description of the behavioural context in which serosorting occurs and the relationship of the different forms of serosorting with the specific outcome of frequencies of bacterial STI. By oversampling participants with higher risk levels, we could do more detailed subgroup analyses, e.g. comparing HIVpositive and HIV-negative participants with different risk management strategies and tactics, and different relationship statuses. This view is supported by the sensitivity analysis where we excluded participants recruited on the bareback website. This analysis showed that the results remain essentially unchanged. Not surprisingly, HIV-positive MSM recruited on the bareback website reported less safer sex, less monogamy and more HIV serosorting than HIV-positive MSM recruited on other websites or offline. Since serosorting for HIV-positive MSM is a form of stigma management, serosorting is easier and more efficient on a bareback website than on general MSM websites due to the high proportion of HIVpositive users. Thus we do not believe that HIV-positive respondents recruited on bareback sites should or need to be excluded from analysis. If we still adjust for recruitment site in our multiple regression analysis, we arrive at a rather conservative estimate of the impact of serosorting on the risk for bacterial STI.

Taken together, HIV serosorting has emerged as the preferred RMA among MSM who are (already) HIV-positive, and hence, can - at least theoretically - serosort comparably effectively. However, UAI, in the context of HIV serosorting, amplifies the incidence and prevalence of STI other than HIV and thus increases the per-contact risks for HIV transmission during serodiscordant sexual encounters particularly in the subgroup of HIV-positive men who are not yet undergoing ART. ${ }^{18,20,21,25,33}$ The high self-reported incidence of bacterial STI among HIV-positive men points to the problem that HIV serosorting may be stigma management rather than sexual risk management, and suggests a serious lack of a comprehensive and adequate STI prevention strategies for this group.

While the importance of prevention activities targeted at HIV-positive persons has repeatedly been emphasised, ${ }^{35-37}$ most proposals relate to activities within the medical care system. However, persons who are not yet eligible for ART appear less frequently in the health care system and would thus be more difficult to reach by such activities. However, most of the HIV-positive persons already receiving ART have an effectively suppressed viral replication and thus probably do not represent an important 
source of onward transmission of HIV - although the extent of HIV transmission risk reduction in the context of concomitant STI is controversial. ${ }^{38-42}$ In any case, our findings suggest that comprehensive screening and treatment for STI should be integrated into routine HIV care for sexually active HIVpositive MSM.

Our data and other reports on the increasing incidence and prevalence of bacterial STI among HIVpositive MSM43 raise doubts about the frequently cited claim that knowledge of one's HIV infection status reduces risky sexual behaviour in the longterm. ${ }^{44}$ At least in our MSM sample, a main component of the changes in risk behaviour is HIV serosorting; serosorting, even if successful, addresses only the risk of HIV and may have contrary effects on the risk for other STI.

In the long-term, our finding of severe unintended side effects of HIV serosorting raises the question how gay communities should deal with the prospect of a slowly but continuously increasing prevalence of HIV in the coming years. A vision other than dividing the gay community socially and sexually into people who are HIV-positive and HIV-negative may be needed.

\section{Conflicts of interest}

None declared.

\section{Authors' contributions}

UM planned and supervised the study; AJS coordinated the study and performed all statistical analyses. AJS andUMdrafted the manuscript with equal contributions. $\mathrm{OH}$ critically revised the manuscript.

\section{Acknowledgements}

We would like to acknowledge the assistance of our colleagues at Robert Koch Institute who contributed to the study, particularly Claudia Kuecherer and her team; and the cooperation of the German MSM websites and private practices, without whom we would not have succeeded in recruiting so many participants; and, of course, the study participants who filled out the questionnaire. The study was financed by a grant from the German Federal Ministry of Health. 


\section{References}

1 Van Kesteren NM, Hospers HJ, Kok G. Sexual risk behaviour among HIV-positive men who have sex with men: a literature review. Patient Educ Couns 2007; 65: 5-20. doi:10.1016/j.pec.2006. 09.003 2 Elford J, Bolding G, Davis M, Sherr L, Hart G. Trends in sexual behaviour among London homosexual men 1998-2003: implications for HIV prevention and sexual health promotion. Sex Transm Infect 2004; 80: 451-4.

3 Elford J. Changing patterns of sexual behaviour in the era of highly active antiretroviral therapy. Curr Opin Infect Dis 2006; 19: 26-32.

4 Parsons JT, Schrimshaw EW, Wolitski RJ, Halkitis PN, Purcell DW, Hoff CC, et al. Sexual harm reduction practices of HIV-seropositive gay and bisexual men: serosorting, strategic positioning, and withdrawal before ejaculation. AIDS 2005; 19: S13-25.

5 Van De Ven P, Kippax S, Crawford J, Rawstorne P, Prestage G, Grulich A, et al. In a minority of gay men, sexual risk practice indicates strategic positioning for perceived risk reduction rather than unbridled sex. AIDS Care 2002; 14: 471-80.

6 Muñoz-Laboy M, Castellanos D, Westacott R. Sexual risk behaviour, viral load, and perceptions of HIV transmission among homosexually active Latino men: an exploratory study. AIDS Care 2005; 17: 33-45.

7 Osmond DH, Pollack LM, Paul JP, Catania JA. Changes in prevalence of HIV infection and sexual risk behavior in men who have sex with men in San Francisco: 1997-2002. Am J Public Health 2007; 97: 1677-83.

8 Mao L, Crawford JM, Hospers HJ, Prestage GP, Grulich AE, Kippax K, et al. 'Serosorting' in casual anal sex of HIV-negative gay men is noteworthy and is increasing in Sydney, Australia. AIDS 2006; 20: 1204-6.

9 Halkitis P, Parsons J, Wilton L. Barebacking among gay and bisexual men in New York City: explanations for the emergence of intentional unsafe behaviour. Arch Sex Behav 2003; 32: 351-7.

10 Sanchez T, Finlayson T, Drake A, Behel S, Cribbin M, Dinenno E, et al. Human immunodeficiency virus (HIV) risk, prevention, and testing behaviors - United States, National HIV Behavioral Surveillance System: men who have sex with men, November 2003-April 2005. MMWR Surveill Summ 2006; 55: 1-16.

11 Calzavara L, Burchell AN, Remis RS, Major C, Corey P, Myers T, et al. Delayed application of condoms is a risk factor for human immunodeficiency virus infection among homosexual and bisexual men. Am J Epidemiol 2003; 157: 210-7.

12 Cassels S, Menza TW, Goodreau SM, Golden MR. HIV serosorting as a harm reduction strategy: evidence from Seattle, Washington. AIDS 2009; 23: 2497-506.

13 Butler DM, Smith DM. Serosorting can potentially increase HIV transmissions. AIDS 2007; 21: 1218-20.

14 Eaton LA, Kalichman SC, O'Connell DA, Karchner WD. A strategy for selecting sexual partners believed to pose little/no risks for HIV: serosorting and its implications for HIV transmission. AIDS Care 2009; 21: 1279-88.

15 Bourne A, Dodds C, Keogh P, Weatherburn P, Hammond G. Relative safety II. London: Sigma Research; 2009.

16 Adam BD, Husbands W, Murray J, Maxwell J. Silence, assent and HIV risk. Cult Health Sex 2008; 10: 759-72.

17 Zablotska IB, Imrie J, Prestage G, Crawford J, Rawstorne P, Grulich A, et al. Gay men's current practice of HIV seroconcordant unprotected anal intercourse: serosorting or seroguessing? AIDS Care 2009; 21: 501-10.

18 Benn PD, Rooney G, Carder C, Brown M, Stevenson S, Copas AJ, et al. Chlamydia trachomatis and Neisseria gonorrhoeae infection and the sexual behaviour of men who have sex with men. Sex Transm Infect 2007; 83: 106-12.

19 Jin F, Prestage GP, Mao L, Kippax SC, Pell CM, Donovan B, et al. Incidence and risk factors for urethral and anal gonorrhoea and chlamydia in a cohort of HIV-negative homosexual men: the Health in Men Study. Sex Transm Infect 2007; 83: 113-119.

20 Jin F, Prestage GP, Zablotska I, Rawstorne P, Kippax SC, Donovan B, et al. High rates of sexually transmitted infections in HIV positive homosexual men: data from two community based cohorts. Sex Transm Infect 2007; 83: 397-9.

21 Dodds JP, Johnson AM, Parry JV, Mercey DE. A tale of three cities: persisting high HIV prevalence, risk behaviour and undiagnosed infection in community samples of men who have sex with men. Sex Transm Infect 2007; 83: 392-6.

22 Truong HH, Kellogg T, Klausner JD, Katz MH, Dilley J, Knapper K, et al. Increases in sexually transmitted infections and sexual risk behaviour without a concurrent increase in HIV incidence among 
men who have sex with men in San Francisco: a suggestion of HIV serosorting? Sex Transm Infect 2006; 82: 461-6.

23 Fleming DT, Wasserheit JN. From epidemiological synergy to public health policy and practice: the contribution of other STD to sexual transmission of HIV infection. Sex Transm Infect 1999; 75: 3-17.

24 Cohen MS, Pilcher CP. Amplified HIV transmission and new approaches to HIV prevention. $J$ Infect Dis 2005; 191: 1391-3.

25 Spielmann N, Münstermann D, Hagedorn H-J, an der Heiden M, Houareau C, GunsenheimerBartmeyer B, et al. Time trends of syphilis and HSV-2 co-infection among men who have sex with men in the German HIV-1 seroconverter cohort from 1996-2007. Sex Transm Infect 2010, in press.

26 Vittinghoff E, Douglas J, McKirnan D, MacQueen K, Buchbinder S. Per-contact risk of human immunodeficiency virus transmission between male sexual partners. Am J Epidemiol 1999; 150: 30612.

27 Samuel MC, Mohr MS, Speed TP, Winkelstein W. Infectivity of HIV by anal and oral intercourse among homosexual men. In: Kaplan EH, Brandeau ML, editors. Modelling the AIDS epidemic: planning, policy, and prediction. New York: Raven; 1994. pp. 423-438.

28 Mustanski BS. Are sexual partners met online associated with HIVI STI risk behaviours? Retrospective and daily diary data in conflict. AIDS Care 2007; 19: 822-7.

29 Davis M, Hart G, Bolding G, Sherr L, Elford J. Sex and the internet: gay men, risk reduction and serostatus. Cult Health Sex 2006; 8: 161-74.

30 Klitzman R, Exner T, Correale J, Kirshenbaum SB, Remien R, Ehrhardt AA, et al. It's not just what you say: relationships of HIV disclosure and risk reduction among MSM in the post-HAART era. AIDS Care 2007; 19: 749-56.

31 Horvath KJ, Oakes JM, Rosser BR. Sexual negotiation and HIV serodisclosure among men who have sex with men with their online and offline partners. J Urban Health 2008; 85: 744-58.

32 Eaton LA, Kalichman S. Risk compensation in HIV prevention: implications for vaccines, microbicides, and other biomedical HIV prevention technologies. Curr HIVIAIDS Rep 2007; 4: 165-72.

33 Kent CK, Chaw JK, Wong W, Liska S, Gibson S, Hubbard G, et al. Prevalence of rectal, urethral, and pharyngeal chlamydia and gonorrhea detected in 2 clinical settings among men who have sex with men: San Francisco, California, 2003. Clin Infect Dis 2005; 41: 67-74.

34 Marcus U, Schmidt AJ, Bochow M. Estimating the regional distribution of men who have sex with men (MSM) based on internet surveys. BMC Public Health 2009; 9: 180.

35 Centers for Disease Control. Incorporating HIV prevention into the medical care of persons living with HIV. MMWR Recomm Rep 2003; 52: 1-24.

36 Wolitski RJ, Parsons JT, Gómez CA, Purcell DW, Hoff CC, Halkitis PN. Prevention with gay and bisexual men living with HIV: rationale and methods of the Seropositive Urban Men's Intervention Trial (SUMIT). AIDS 2005; 19: S1-11.

37 Gordon CM, Forsyth AD, Stall R, Cheever LW. Prevention interventions with persons living with HIVIAIDS: state of the science and future directions. AIDS Educ Prev 2005; 17: 6-20.

38 Vernazza PL, Troiani L, Flepp MJ, Cone RW, Schock J, Roth F, et al. Potent antiretroviral treatment of HIV-infection results in suppression of the seminal shedding of HIV. The Swiss HIV Cohort Study. AIDS 2000; 14: 117-21.

39 Cohen MS, Hoffman IF, Royce RA, Kazembe P, Dyer JR, Daly CC, et al. Reduction of concentration of HIV-1 in semen after treatment of urethritis: implications for prevention of sexual transmission of HIV-1. Lancet 1997; 349: 1868-73.

40 Sadiq ST, Taylor S, Kaye S, Bennett J, Johnstone R, Byrne P, et al. The effects of antiretroviral therapy on HIV-1 RNA loads in seminal plasma in HIV-positive patients with and without urethritis. AIDS 2002; 16: 219-25.

1250-00011 41 Graham SM, Holte SE, Peshu NM, Richardson BA, Panteleeff DD, Jaoko WG, et al. Initiation of antiretroviral therapy leads to a rapid decline in cervical and vaginal HIV-1 shedding. AIDS 2007; 21: 501-7.

42 Vernazza P, Hirschel B, Bernasconi E, Flepp M. HIV-infizierte Menschen ohne andere STD sind unter wirksamer antiretroviraler Therapie sexuell nicht infektiös. Schweiz Arzteztg 2008; 89: 165-9.

43 Williamson LM, Dodds JP, Mercey DE, Hart GJ, Johnson AM. Sexual risk behaviour and knowledge of HIV status among community samples of gay men in the UK. AIDS 2008; 22: 1063-70. 44 Marks G, Crepaz N, Senterfitt JW, Janssen RS. Meta-analysis of highrisk sexual behavior in persons aware and unaware they are infected with HIV in the United States: implications for HIV prevention programs. J Acquir Immune Defic Syndr 2005; 39: 446-53. 


\section{Tables}

Table 1 Risk management approaches which were analysed and how they were queried

\begin{tabular}{ll} 
Risk management approach & Question (Q) \\
& Answer (A) \\
\hline Strategic serosorting & Q: What is your response to the risk of in fections during sexual contacts? \\
A: I prefer having sex with men with the same HIV serostatus \\
Q: Under which conditions would you decide not to use a condom for anal intercourse? \\
A: If my partner has the same HIV serostatus or if I have the impression that my partner is infected with HIV [respondents \\
who report being HIV-positive] \\
If I have the impression that my partner is HIV-negative [respondents who report being HIV-negative] \\
Q: What is your response to the risk of infections during sexual contacts? \\
A: I practice safer sex \\
Q: What is your response to the risk of infections during sexual contacts? \\
Monogamy & A: I concentrate on steady relationships \\
& Q: Under which conditions would you decide not to use a condom for anal intercourse? \\
Partner decision & A: If my partner does not insist on condom use \\
Q: Is the risk of acquiring an STI other than HIV a reason for you to use condoms? & A: Yes \\
Extended condom use & Q: What is your response to the risk of in fections during sexual contacts? \\
Face check & Q: I check what my partners look like \\
Withdrawal & A: I withdraw my penis before ejaculation \\
Q: Under which conditions would you decide not to use a condom for anal intercourse?
\end{tabular}

${ }^{A}$ No definition of safer sex was provided in the questionnaire. 
Table 2 Basic characteristics of survey participants according to reported HIV serostatus, sexual behaviour and selected risk management approaches among respondents with a previous HIV test

\begin{tabular}{|c|c|c|c|}
\hline & HIV-negative $(n=2187)$ & HIV-positive $(n=798)$ & $P$-value \\
\hline Median age (range) & $34(16-76)$ & $40(20-70)$ & $P<0.001$ \\
\hline $\begin{array}{l}\text { Geographic distribution (city size) } \\
<20000 \\
20000-100000 \\
100000-500000 \\
500000-1 \text { million } \\
>1 \text { million }\end{array}$ & $\begin{array}{l}18.1 \% \\
19.8 \% \\
22.2 \% \\
12.6 \% \\
27.2 \%\end{array}$ & $\begin{array}{l}11.6 \% \\
13.5 \% \\
20.9 \% \\
14.7 \% \\
39.4 \%\end{array}$ & $P<0.001$ \\
\hline $\begin{array}{l}\text { Recruitment site } \\
\text { Practices } \\
\text { General dating sites } \\
\text { Bareback site } \\
\end{array}$ & $\begin{array}{r}10.1 \% \\
83.1 \% \\
6.8 \% \\
\end{array}$ & $\begin{array}{l}46.5 \% \\
25.1 \% \\
28.4 \% \\
\end{array}$ & $P<0.001$ \\
\hline $\begin{array}{l}\text { Educational status } \\
\text { Low ( } 9 \text { years of schooling or less) } \\
\text { Medium } \\
\text { High ( } 12 \text { years of schooling or more) }\end{array}$ & $\begin{array}{l}14.1 \% \\
31.9 \% \\
54.0 \%\end{array}$ & $\begin{array}{l}16.4 \% \\
35.2 \% \\
48.4 \%\end{array}$ & $P=0.044$ \\
\hline $\begin{array}{l}\text { Relationship or civil status } \\
\text { Single } \\
\text { Heterosexual partnership } \\
\text { Homosexual partnership (HP) } \\
\text { Among HP: monogamous } \\
\text { Among HP: non-monogamous } \\
\text { Among HP: seroconcordant } \\
\text { Among HP: serodiscordant } \\
\text { Partner's serostatus unknown }\end{array}$ & $\begin{array}{c}44.5 \% \\
7.6 \% \\
47.9 \%(n=1048) \\
46.1 \% \\
53.9 \\
65.9 \\
9.1 \% \\
25.0 \%\end{array}$ & $\begin{array}{c}45.9 \% \\
3.6 \% \\
50.5 \%(n=402) \\
24.6 \% \\
75.4 \% \\
43.1 \% \\
37.5 \% \\
19.4 \%\end{array}$ & $\begin{array}{l}P<0.001 \\
P<0.001 \\
P<0.001 \\
P<0.001 \\
P<0.001 \\
P<0.001 \\
P<0.001\end{array}$ \\
\hline $\begin{array}{l}\text { Sexual behaviour in the previous } 12 \text { months } \\
\text { More than } 10 \text { sexual partners } \\
\text { Non-steady partners predominantly anonymous } \\
\text { Unprotected anal intercourse with non-steady partners }\end{array}$ & $\begin{array}{r}32.4 \% \\
36.3 \% \\
7.0 \%\end{array}$ & $\begin{array}{l}54.8 \% \\
53.4 \% \\
27.7 \%\end{array}$ & $\begin{array}{l}P<0.001 \\
P<0.001 \\
P<0.001\end{array}$ \\
\hline $\begin{array}{l}\text { Risk management approaches } \\
\text { Strategic serosorting } \\
\text { Tactical serosorting } \\
\text { Safer sex } \\
\text { Monogamy } \\
\text { Partner decision } \\
\text { Extended condom use } \\
\text { Face check } \\
\text { Withdrawal } \\
\text { Strategic positioning }\end{array}$ & $\begin{array}{r}12.6 \% \\
45.1 \% \\
79.0 \% \\
37.1 \% \\
6.2 \% \\
85.5 \% \\
17.4 \% \\
7.5 \% \\
11.3 \%\end{array}$ & $\begin{array}{r}37.2 \% \\
55.1 \% \\
52.6 \% \\
20.4 \% \\
27.4 \% \\
70.3 \% \\
14.9 \% \\
9.0 \% \\
17.8 \%\end{array}$ & $\begin{array}{l}P<0.001 \\
P<0.001 \\
P<0.001 \\
P<0.001 \\
P<0.001 \\
P<0.001 \\
P=0.104 \\
P=0.159 \\
P<0.001\end{array}$ \\
\hline Bacterial sexually transmissible infections in the past 12 months & $9.0 \%$ & $33.1 \%$ & $P<0.001$ \\
\hline
\end{tabular}

${ }^{A}$ Five or more episodes of unprotected anal intercourse with non-steady partners of unknown HIV serostatus in the previous 12 months. 
Table 3 Relationship of strategic and tactical serosorting with other risk management approaches Age and recruitment site adjustedA odds ratios with 95\% confidence intervals. HIV-positive and HIVnegative strategic and tactical serosorters were compared

with their respective non-serosorting control groups, after exclusion of all respondents who reported a primary seroconcordant partner $(n=938)$

\begin{tabular}{|c|c|c|c|c|c|}
\hline & \multirow{2}{*}{$\begin{array}{l}\text { Without seroconcordant partner } \\
(N=2047)\end{array}$} & \multicolumn{2}{|c|}{ Strategic serosorters } & \multicolumn{2}{|c|}{ Tactical serosorters } \\
\hline & & HIV-negative & HIV-positive & HIV-negative & HIV-positive \\
\hline & Serosorters $v$. non-serosorters $(n)$ & 181 v. 1275 & 198 v. 393 & 636 v. 820 & 295 v. 296 \\
\hline \multirow[t]{3}{*}{ Behaviour $^{\mathrm{E}}$} & More than 10 sexual partners & n.s. ${ }^{B}$ & $2.04(1.38-3.02)$ & n.s. & $2.38(1.66-3.41)$ \\
\hline & $\begin{array}{l}\text { Non-steady partner, } \\
\text { predominantly anonymous }{ }^{\mathrm{C}}\end{array}$ & $0.67(0.47-0.94)$ & n.s. & $0.77(0.62-0.97)$ & n.s. \\
\hline & $\begin{array}{l}\text { Unprotected anal intercourse } \\
\text { with non-steady partners }{ }^{\mathrm{D}}\end{array}$ & n.s. & $2.51(1.67-3.76)$ & $3.00(1.97-4.56)$ & $3.44(2.26-5.25)$ \\
\hline \multirow{8}{*}{$\begin{array}{l}\text { Risk management } \\
\text { approaches }\end{array}$} & Tactical serosorting & $2.89(2.05-4.08)$ & $21.93(12.54-38.35)$ & - & - \\
\hline & Safer sex & n.s. & $0.27(0.18-0.40)$ & $0.46(0.35-0.60)$ & $0.27(0.19-0.40)$ \\
\hline & Monogamy & $1.51(1.08-2.11)$ & n.s. & $1.50(1.19-1.90)$ & n.s. \\
\hline & Partner decision & n.s. & $1.90(1.27-2.86)$ & $1.77(1.15-2.73)$ & $1.77(1.17-2.63)$ \\
\hline & Extended condom use & n.s. & $0.29(0.20-0.45)$ & $0.51(0.38-0.68)$ & $0.31(0.20-0.47)$ \\
\hline & Face check & $1.77(1.24-2.54)$ & n.s. & $2.10(1.60-2.75)$ & n.s. \\
\hline & Withdrawal & $2.05(1.26-3.35)$ & n.s. & $1.50(1.01-2.23)$ & n.s. \\
\hline & Strategic positioning & n.s. & $2.53(1.59-4.02)$ & $2.39(1.72-3.31)$ & $2.58(1.58-4.21)$ \\
\hline
\end{tabular}

${ }^{\text {A }}$ Odds ratios are adjusted for age groups $16-24$ years $(n=258), 25-34$ years $(n=608), 35-44$ years $(n=764)$ and $45+(n=417)$, and for recruitment site.

${ }^{B}$ Non-significant at alpha $=0.95$.

${ }^{\mathrm{C}}$ Non-steady partners are predominantly anonymous partners.

${ }^{D}$ Five or more episodes of unprotected anal intercourse with non-steady partners of unknown HIV serostatus.

${ }^{\mathrm{E}}$ Sexual behaviour in the past 12 months.

Example: HIV-negative tactical serosorters have three-fold higher odds of reporting five or more episodes of unprotected anal intercourse with non-steady partners of unknown HIV status compared to HIV-negative respondents who do not report tactical serosorting.

Table 4 Self-reported bacterial sexually transmissible infections (STI) in the previous 12 months in different strata of serosorters compared with non-serosorting control groups

Age- and recruitment site-adjusted odds ratio with 95\% confidence intervals. HIV-positive and HIVnegative strategic and tactical serosorters with and without seroconcordant partners were compared with their respective non-serosorting control groups. Odds ratios are adjusted for age groups 16-24 years ( $n=258), 25-34$ years $(n=608), 35-44$ years $(n=764)$ and $45+(n=417)$, and recruitment site

\begin{tabular}{|c|c|c|c|c|}
\hline \multirow[b]{2}{*}{ Without seroconcordant partner $(N=2047)$} & \multicolumn{2}{|c|}{ Strategic serosorters } & \multicolumn{2}{|c|}{ Tactical serosorters } \\
\hline & HIV-negative & HIV-positive & HIV-negative & HIV-positive \\
\hline Serosorters $v$. non-serosorters $(n)$ & 181 v. 1275 & 198 v. 393 & 636 v. 820 & 295 v. 296 \\
\hline Bacterial STI past 12 months & n.s. ${ }^{\wedge}$ & $2.62(1.76-3.89)$ & n.s. & $3.19(2.14-4.75)$ \\
\hline Serosorters $v$. non-serosorters & $9.9 \%$ v. $9.2 \%$ & $48.0 \%$ v. $23.4 \%$ & $10.7 \%$ v. $8.2 \%$ & $45.4 \%$ v. $17.9 \%$ \\
\hline With seroconcordant partner $(N=938)$ & HIV-negative & HIV-positive & HIV-negative & HIV-positive \\
\hline Serosorters $v$. non-serosorters $(n)$ & 95 v. 636 & 99 v. 108 & 350 v. 381 & 145 v. 62 \\
\hline Bacterial STI past 12 months & n.s. & $2.58(1.36-4.89)$ & n.s. & $3.17(1.47-6.83)$ \\
\hline Serosorters $v$. non-serosorters & $9.5 \%$ v. $8.3 \%$ & $49.5 \%$ v. $25.9 \%$ & $9.4 \%$ v. $7.6 \%$ & $45.5 \%$ v. $17.7 \%$ \\
\hline
\end{tabular}

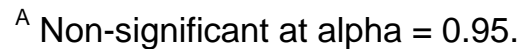

